\title{
Complicated Relationships: A Review of Biological Interaction Networks and Pathways in Animal Science
}

\author{
Brian Karisa • Stephen Moore • Graham Plastow
}

Received: 24 February 2013/Revised: 9 June 2013/Accepted: 12 June 2013/Published online: 21 June 2013

(c) Springer International Publishing AG 2013

\begin{abstract}
The availability of high-throughput genomic technologies has resulted in the identification of millions of DNA polymorphisms, candidate genes and metabolites associated with several economically important traits in livestock production. However, despite the increase in DNA markers and candidate genes associated with these productivity traits, only a small proportion of phenotypic variation in these traits can be explained. This missing heritability creates a need to address the other levels of regulation of gene expression such as the levels occurring post-translation including metabolites. There is also need to use biological network analysis to understand the complex relationships and interactions among genes, metabolites, and markers in shaping the traits of economic importance in livestock production. At the moment, biological network analysis is still in its infancy in animal science; however, it has a great potential to create a holistic view of the underlying biological mechanisms associated with the variation in important traits in livestock production. The goal is to describe some of the approaches used to identify novel DNA variants associated with economically important traits in livestock and address biological interaction network reconstruction, analysis, and application in research in animal science.
\end{abstract}

Keywords Gene networks - Metabolic networks · Pathways

B. Karisa $(\bowtie) \cdot$ S. Moore $\cdot$ G. Plastow

Agriculture and Forestry Center, University of Alberta,

Edmonton, AB T6G2P5, Canada

e-mail: bkarisa@ualberta.ca

G. Plastow

e-mail: plastow@ualberta.ca

\section{Introduction}

Profits in any enterprise are defined as the difference between costs and returns. In livestock production, profits can be increased by reducing the costs of production (inputs) and/or by increasing the returns. Returns can be increased by increasing production and/or by increasing the price of the product. Considering the limited capacity to increase production, farmers may seek to emphasize quality so as to increase the price of the product.

In most livestock production systems, the cost of feed is the largest single expense (input). It accounts for between 60 and $70 \%$ of the total cost of production in beef cattle [3, 29], about $65 \%$ of total costs in pigs [32], and approximately $70 \%$ in broilers [1]. On the other hand, production traits (outputs) differ across different livestock production systems such as eggs and meat in poultry production, milk in dairy production, and meat in beef cattle and pig production systems. These production traits influence the economic success in livestock production, which relies on producing products of high economic value at the lowest cost possible [50].

Most of the traits that are of economic importance to livestock producers are quantitative in nature; they are influenced by multiple genes, each causing a small effect on the trait. In addition, most economically important traits are correlated. Therefore, selecting individuals for one trait could impact upon another trait.

In the past, selection of individuals for economically important traits was solely based on phenotypic measurements and statistical predictions using information collected from relatives [14]. Although this strategy has had several successes, the advent of genetic markers for marker-assisted selection has the potential to increase the accuracy of selection and reduce generation interval 
resulting in an increase in the response to selection [73]. Genetic markers are especially important when it is expensive to collect the required phenotypic data on the traits of interest, or in traits, such as carcass traits, which cannot be measured until the animal has been sacrificed making it unavailable for breeding.

The growing need to use genetic markers for selecting animals for breeding has resulted in a surge in highthroughput genomic techniques and the generation of large amounts of data on DNA polymorphisms and potential candidate genes [64]. However, despite the increase in DNA markers and candidate genes associated with several economically important traits, only a small proportion of the phenotypic variation in quantitative traits can be explained by the genetic markers [64]. The amount of variation explained by DNA markers is even lower when the effects of the same markers are assessed in unrelated populations. This can be partly attributed to the nature of association between the DNA markers and the trait, which may either be statistical or functional. Statistical association is based on linkage disequilibrium (LD) between the marker and the causal DNA variant [73]. Statistical association indicates that the marker associated with the variation in the trait of interest may not be causing the phenotypic variation; however, it is inherited together with the unknown functional DNA variant more frequently than by random chance; that is, the marker is in LD with the functional DNA variant. Statistical associations are relatively more difficult to replicate across different populations [73] possibly due to decay of LD resulting in different LD patterns between different populations especially populations separated by geographical isolation [19]. Functional association analysis, on the other hand, utilizes DNA markers with functional relevance to the biological mechanisms regulating a trait. As a result, these markers may be associated with a larger effect on the variation of the corresponding trait and because they do not rely necessarily on $\mathrm{LD}$, they are expected to be reproducible across diverse populations offering more accurate and reproducible predictions of the levels of the trait even in untested populations [73]. For example, a functional variant observed in the MC4R gene has been shown to have consistent effects on pig growth and fat deposition traits across populations and environments [42-44, 78].

This missing heritability has been attributed to several factors reviewed in detail by Maher [51] and Hill [30]. These factors include:

- Statistical errors arising from the models including markers that are identified to be significantly associated with a trait when they are in fact false positives.

- The contribution of many loci to the trait's variation [81]. This is the infinitesimal model first described by
Fisher [20] indicating that quantitative traits are regulated by possibly an infinite number of genes each with a small effect on the trait [6]. This concept was also illustrated by Nagamine et al. [57] who developed an analytical approach to detect regions containing multiple alleles that individually contribute too little variance to be detectable by genome-wide association studies.

- Transient epigenetic effects could contribute to heritability estimates from close relatives [72].

- Interaction between DNA variants with differing effects on the same trait that may even cause diluting effects to each other. This is illustrated in animals by PRKAG3 [10] and MC4R [18].

- Interaction between different DNA variants with differing effects on different traits (pleiotropy) though these were suggested to be rare [79].

- Interaction between alleles at the same loci resulting in varying degrees of dominance effects which cannot be detected in the heritability of a trait.

In this review, we discuss some of the approaches used to identify DNA markers associated with economically important traits. We also explore the use of biological networks in analyzing the interactions among candidate genes, DNA polymorphisms, metabolites; and understanding the biological pathways involved in regulation of gene expression for productivity traits.

\section{Association Analysis}

In biological sciences, association analysis refers to the process of finding variations in different boundaries of cellular processes or molecules and assessing their correlation with the variation in a trait. These boundaries are referred to as levels of constraints or control constraints [76] outlined in Fig. 1. The molecules may be at the DNA level (marker genotypes) or at the level of metabolites (such as hormones and enzymes). The primary objective in association analysis is to develop markers (genetic, metabolic, etc.) that could be used to accurately predict the level of a trait without necessarily obtaining the phenotypic data on the trait.

There are two major approaches used to perform association analysis in animal sciences; the quantitative trail locus/loci (QTL) mapping approach and the candidate gene approach.

\section{The QTL Mapping Approach}

QTL mapping describes the approach used to identify chromosome regions associated with variation in quantitative 
Fig. 1 Levels of regulation of gene expression from DNA to metabolites

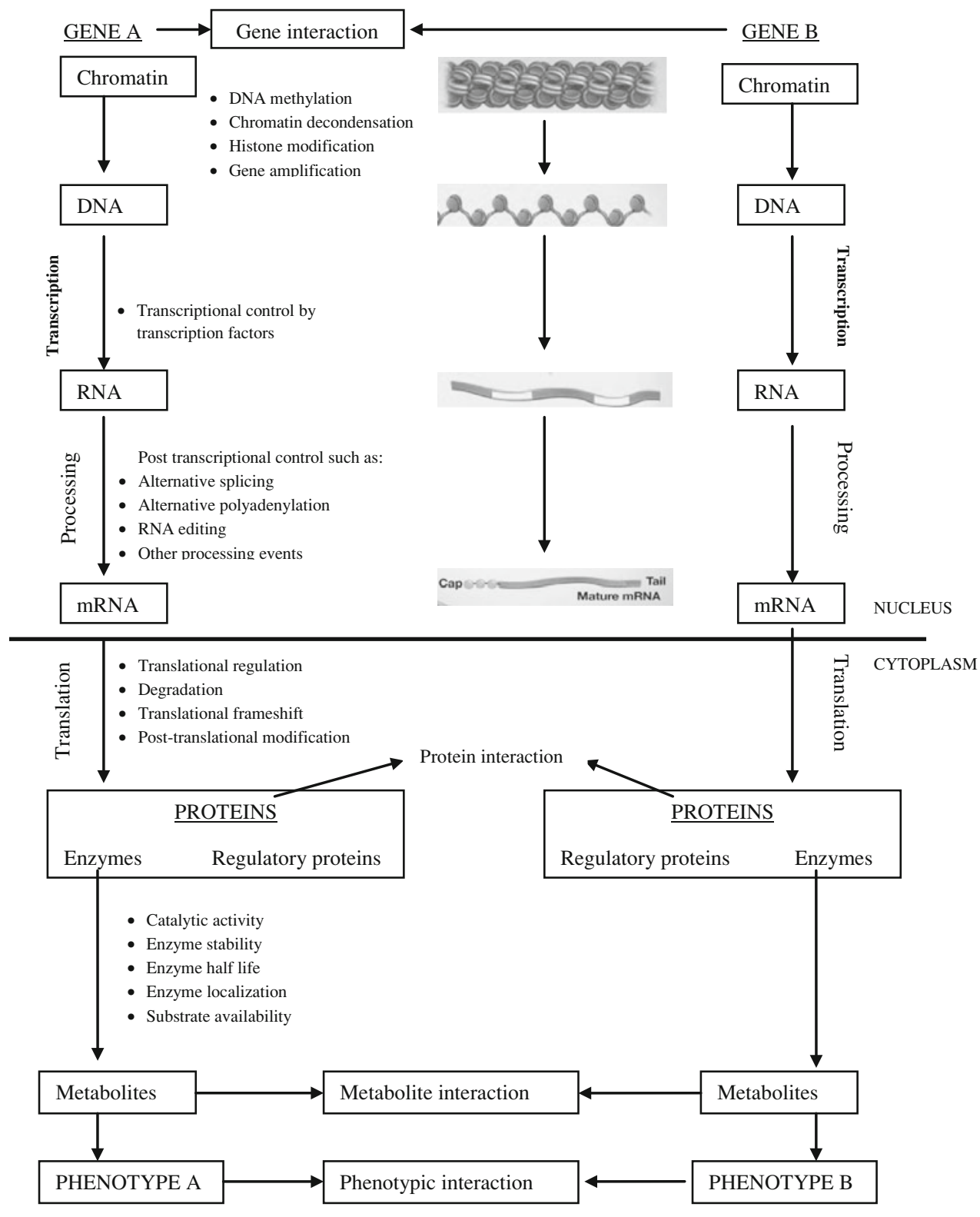

traits. This approach assumes that the actual genes and functional DNA variants associated with the trait are unknown and instead it identifies DNA markers that are in LD with the causative DNA variants [28].

QTL mapping can be classified as either family based (classical) or population based (association analysis). Classical QTL mapping relies on experimental populations of animals that are developed by breeding specific individuals or lines to maximize the LD in families. Family-wise LD decays through recombination after a few generations of random mating; therefore, it is not long term [28]. Alternatively, QTL mapping may be performed using naturally occurring populations and thereby exploit population-wise LD as shown in Evans et al. [17]. This approach differs from classical QTL mapping because population-wise LD has undergone several recombination events resulting from random mating. Population-wise LD persists for a longer period across a larger number of generations than family-wise LD [28]. A detailed review of QTL mapping was discussed by Hayes [28].

\section{The Candidate Gene Approach}

The candidate gene approach is a functional association approach, which assumes that a gene whose function is related to the physiology of the trait contains a polymorphism that causes variation in that trait [28]. Unlike QTL mapping which identifies markers linked to the gene, the 
candidate gene approach identifies potential causative gene(s) that contain(s) DNA variant(s) associated with phenotypic variation in the trait of interest [86].

The candidate gene approach consists of four strategies:

The comparative genomics strategy is used to identify candidate genes in particular species by comparing the structure and functions of candidate genes in other species assuming that genes may be functionally conserved or structurally homologous [86]. This approach has been utilized in mouse models to identify putative genes that confer susceptibility to human diseases [55]. In addition, the approach was also applied after the identification of the role of CAST gene in meat tenderness in cattle [68] to identify its role in influencing meat tenderness in other species such as sheep [45]. The predictions are occasionally inefficient because of the biological differences among species due to the genetic heterogeneity and evolutionary differentiation [86].

The position-dependent strategy utilizes physical linkage of genes in a QTL region [86]. This strategy aims at known QTL regions with the genes located in their vicinity considered as candidates. Successful applications of the position-dependent strategy have been reported in previous studies including the association between a missense mutation located in the DGAT1 gene and milk yield and composition in cattle [24] and that in PRKAG3 gene with glycogen content in skeletal muscles in pigs [9, 54].

In addition, DNA polymorphisms located in the GDF8/ MSTN gene were shown to be associated with carcass traits in sheep [37], double muscling and racing performance in dogs [56], and double muscling in cattle [53]. Associations between haplotypes of the IGF1 gene with body size in dogs were reported by Sutter [77]. The difficulty in this strategy is to prioritize the positional candidate genes to identify the genes with more functional relevance to the trait.

The function-dependent strategy aims at identifying genes whose biological functions are related to the physiological processes causing variation in a trait. It could use gene expression profiles associated with the trait and/or information from gene knock-out and transgenic animals [86]. The function-dependent strategy was used by (among others) [67] to identify the association between ESR gene and litter size in pigs.

The last strategy is the combination strategy that may involve a combination of two or more of the three aforementioned strategies. For example, the position-dependent strategy could be combined with mRNA expression profiles to identify candidate genes associated with a trait as reported by Kelly et al. [41]. The combination strategy was also used by Liu et al. [49] to identify genes that confer resistance to Marek's disease among resistant and susceptible chickens, and by Schwerin et al. [70] to identify functional candidate genes associated with mastitis in dairy cattle. Other studies that utilized the combination strategy include [9]; to identify new alleles in the protein kinase adenosine monophosphate-activated gamma (3)-subunit gene and their association with low glycogen content in pig skeletal muscle resulting in improved meat quality and [10]; to identify alleles in the CAST gene and their association with meat quality in pigs. Some additional mutations identified using the candidate gene approaches were reviewed by Andersson and Georges [2].

Metabolites as Intermediate Phenotypes in Association Analysis

If the gene is considered as the start point and the phenotype (trait) is considered as the end point (Fig. 1), all the parameters that are involved in the development of the end point can be considered as intermediate phenotypes. However, certain conditions, as described by Kronenberg [47], need to be met before the parameter can be considered as a suitable intermediate phenotype. The most important of these conditions is that the parameter should be as close to the end point as possible. The intermediate phenotype should also considerably decrease the heterogeneity of the end point phenotype, which dramatically increases the power to detect a gene influencing the intermediate phenotype. If the association between a gene and an intermediate phenotype is strong and the gene has a huge effect on the intermediate phenotype then we can be optimistic that the gene would also have a strong effect on the endpoint. If the effect is low, then we will be warned in advance that the association with the endpoint may be even lower and, therefore, the gene may be of less relevance [47].

Significant associations between genetic and metabolic markers and phenotypes have been reported; [82] reported significant association between mutations in the $N C A P G$ and $G D F 8$ genes and average daily gain in two independent populations of cattle. These authors also observed a significant association between the mutation in the NCAPG with plasma levels of carnitine, arginine, and total dimethylarginine. These results indicate that the significant metabolites could be utilized as intermediate phenotypes linking average daily gain in cattle and the mutation in NCAPG gene. In a separate study, Pliakogiannis et al. [61] reported significant association between serum carnitine levels and body weight and serum triglyceride levels in humans. If validated, the metabolites reported in these studies may have the potential to be used as intermediate phenotypes in selection of cattle for average daily gain and prediction of body weight in humans, respectively.

Therefore, metabolites, as intermediate phenotypes, can be used as biomarkers to predict the levels of certain traits, 
where measuring the levels of the metabolite offers more convenience than measuring the phenotype. However, for these predictions to be highly accurate there should be high correlation between the phenotype and the levels of the metabolite(s).

\section{Biological Networks}

When several parameters such as DNA polymorphisms, genes, and metabolites are associated with a trait, the level of the endpoint is no longer the sum of the individual effects; it is also determined by the modes of interactions between the parameters generally called biological networks [27].

In biological networks a node defines the component molecule being analyzed; it could be a gene (gene network), a metabolite (metabolic network), a protein (protein network), RNA (RNA network), or regulatory networks [4]. The number of links to a node is defined as $k$ or node's degree or connectivity and most nodes have multiple links. The highly connected nodes in a network are called hubs consisting of molecules having a major biological role and are expected to be older and more conserved across individuals and species [4]. Molecules located at the periphery of the network (peripheral nodes) may play a major role on the specific trait of interest but do not have a big impact on other traits due to their low connectivity. It is hypothesized that mutations or deletions of genes at the hub will cause effects on multiple traits compared to mutations located in genes located away from the hub. Trait modules can be developed from the hypothesis that if a gene is involved in regulating a certain trait, the genes that interact with it will also be involved in that trait and the direction of interaction relates to the direction of regulation [4]. An illustration of the features of biological networks is shown in Fig. 2.

There are three major types of biological networks in animal science; gene, metabolic, and phenotypic networks.

\section{Gene and Metabolic Networks}

Gene networks are a reconstruction of the biological processes that result in interactions between multiple genes [15]. Metabolic networks consist of metabolites as the nodes and biochemical reactions transforming these metabolites into each other [60]. These biochemical processes usually utilize enzymes to convert substrates to products. The product of the reaction becomes the substrate for the subsequent step in the biochemical pathway. Therefore, variations in the substrate may cause variation in the levels of products formed, resulting in metabolic interaction. Other metabolites may act as inhibitors or enhancers acting at specific steps along the biochemical

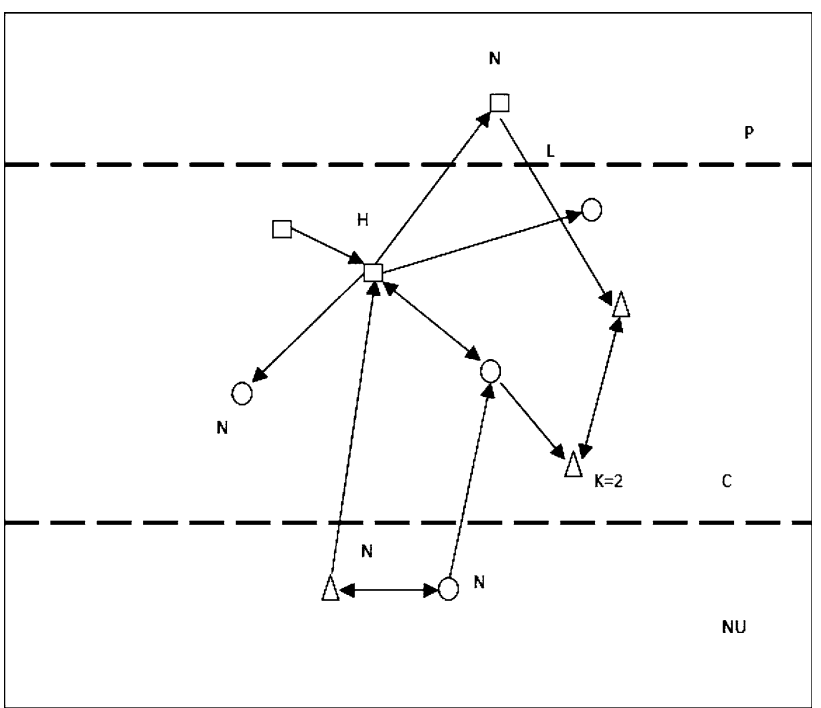

Fig. 2 General characteristics of a biological network with nodes $(\mathrm{N})$, which may represent a gene or a metabolite in gene and metabolic networks, respectively. The locations in the cell where the nodes exert their function are indicated such as plasma membrane $(\mathrm{P})$, cytoplasm (C), or nucleus (NU). Interacting nodes are represented by links (L) whose direction indicates the flow of regulation. The level of connectivity $(\mathrm{k})$ of a node is the number of links to that node and regions with highly connected nodes are called hubs $(\mathrm{H})$. The different shapes of the nodes represent molecules belonging to different functional groups such as enzymes, regulatory proteins, or receptors

pathways and also causing variation in the levels of products formed [60]. A metabolic pathway, therefore, indicates all the possible interactions that can exist between several metabolites and using information on the pathway, one can determine whether the effect is a reduction or an increase in the levels of the product.

\section{Phenotypic Networks}

Phenotypic networks are characterized by phenotypes as nodes and the links represent biological processes and molecular relationships that are common between the interacting traits [4]. Phenotypic networks can, therefore, be inferred using correlations between individual traits. However, although phenotypic correlation matrices indicate the interactions which can be used to infer the networks, they do not indicate the biological processes that cause the interactions. Phenotypic networks have been used more extensively in human disease studies to develop the "human diseasome" [23]. Although no phenotypic network has been constructed for economically important traits in livestock, uncovering links between traits would help to understand how traits that phenotypically appear different may be linked at the molecular level. These networks may be used to predict the effects of selecting animals for one trait on the other linked traits. This technique, therefore, 
offers new approaches to developing complex animal breeding programs and the economic weights used for various traits when developing selection indices.

\section{Analysis and Manipulation of Biological Networks}

Biological networks can be reconstructed using various datasets including lists of genes or metabolites from association studies, results from gene expression studies, or matrices consisting of phenotypic correlations. Programs such as IPA (Ingenuity systems) can reconstruct networks using lists of genes or metabolites while programs such as GenePath [88] infer pathways from gene expression data and Vector PathBlazer [63] reconstructs the networks from a combination of information from different databases.

There are several approaches to the analysis of biological networks including visualization [38]. Tools such as Pathway Editor [74] can be used to manually create visualizations while programs such as Pathway Studio [58], PathwayFinder [85], and PubGene [35] use information in databases to build and create visualization of the pathways. The layout of the biological network is usually automated by the program [87]. However, the automated layout may lack specific biological information such as sub-cellular localization of the respective gene in the cell (as shown in Fig. 2). In IPA, (and possibly other programs) the user can customize the information required in the network and its layout.

Using Pathway Studio [58] the user can interactively expand specific molecules and complexes to show specific regions of the network more clearly. Some programs such as IPA (Ingenuity Systems) assign different shapes for the nodes which represent different molecule classes such that the shape representing an enzyme will be different from the shape representing a receptor.

Comparative analysis of the topology of a biological network can aid in identifying the underlying biological functions associated with the trait. For example, if networks were reconstructed for different animal species, the user can use PathBlast [40] to identify network differences and the biological functions associated with them.

Osprey [5] is a program that can superimpose a network on top of another to identify similarities and differences between them [87]. Biological networks can also be filtered so as to visualize only specific nodes or links [87]

In programs such as IPA (Ingenuity Systems) a list of biological pathways will be created with a corresponding significance value ( $-\log P$ value) for each pathway and compared against a threshold to identify the biological pathways significantly associated with the phenotype in study. A detailed analysis of each pathway can be obtained in the canonical pathway analysis section within the program, which is a database of biochemical pathways, involving genes, proteins, or metabolites (Ingenuity Knowledgebase).

By using these analysis tools, the nature of interactions existing between molecules in the nodes of any biological network and the biological processes underlying certain traits can be identified.

\section{Examples of Biological Networks in Animal Science}

The advent of high-throughput genotyping and sequencing techniques and the completion of whole genome sequencing in several animal species including cattle [16], pig [25], and chicken [31] have led to a rapid increase in molecular data and the discovery of several genes [52, 64]. This genomic revolution has also provided tools to investigate the interactions among genes and their association with phenotypes of economic importance in livestock production. Once discovered, the genes, networks, and biological processes will provide a more complete and accurate understanding of the respective traits and could be used to make predictions of complex traits when phenotypic values are unavailable [52].

\section{Cattle}

Productivity in cattle relies on the efficiency of feed utilization (input) and the quality and quantity of production. The economically important traits depend on the production system such as average daily gain and meat quality in beef and pig operations, milk quantity and quality and reproductive traits in dairy operations, reproductive traits in cow-calf operations, and fiber in wool-sheep and alpaca operations. Other traits of importance include resistance or susceptibility to diseases and fertility.

A gene network containing 3,159 genes associated with 22 measures related to puberty, fertility, growth, and body composition in beef cattle heifers was reconstructed by [21]. Among other benefits, this study showed that the gene network approach captured more information than analyses that utilize LD only. This study was followed up with the analysis of gene networks associated with ten growth and fertility traits in Brangus heifers [22]. These authors reported the importance of genes involved in biological processes such as axon guidance (a pathway known to influence release of LHRH), regulation of cellular localization, regulation of neurotransmitter secretion, and regulation of membrane potential. In addition, the authors identified 5 transcription factors that were located as hubs in the network indicating that their regulatory role may impact the entire network.

Jiang et al. [36] described a candidate gene association and gene network analysis for 19 traits related to carcass 
quality and eating quality in Wagyu $\times$ Limousin crosses. These traits included phenotypic measurements for carcass weight, carcass rib eye area, subcutaneous fat, pelvic and heart fat, and marbling; and taste panel measurements for tenderness, juiciness, and flavor. These traits were generally classified into three categories; carcass measurements, eating quality, and fatty acid composition. They identified 10 genes associated with carcass measurements, 7 genes associated with eating quality, and 5 genes associated with fatty acid composition. Through gene network analysis, the authors reported that the three classes of phenotypes did not share a lot of gene networks indicating a high degree of genetic independence between them. Therefore, the authors concluded that marker-assisted selection to improve one category of these traits would not interfere with the improvement of another category.

Seo and Lewin [71] set out to create a cattle-specific metabolic pathway database using the MetaCyc database [8] and the PathwayTools software [39]. Using comparative analysis of metabolic pathways, the authors revealed the absence of mammalian genes for 22 metabolic enzymes whose activities were reported in the literature. For example, the cattle orthologs of human genes ECGF1, CERK, FAAH2, ALG12, and EARS2 were not identified. This may have resulted from the fact that the generated metabolic network highly depends on the primary genome annotation [59], which is heavily dependent on sequence homology to human and mouse [12].

Hudson et al. [34] proposed a new algorithm to correctly identify the gene containing causal mutation with microarray data using bovine myostatin mutants. This approach identified the causal mutation by globally contrasting coexpression network dynamics. The authors used the differential wiring method to compare RNA expression levels at several developmental stages and contrasted them between the Wagyu and Peidmontese phenotypic differences. They developed a correlation expression network to identify those nodes in the network whose links with other nodes changed significantly between the two breeds and termed these as differential wiring. Then using expression levels for the genes and the level of differential wiring, they developed an algorithm that defined a regulatory impact factor such that genes that were highly expressed and had high differential wiring were defined to have a high regulatory impact factor. They further propose that this approach can be applied to other 'omics data because its mathematical approaches mesh well with the known biology of regulatory and nonregulatory molecules. This proposal was tested by Reverter et al. [65] to identify regulators associated with phenotypic differences in breast cancer and adipocyte differentiation and showed that it appeared universally applicable.

A metabolic network was reconstructed using 1,743 metabolites in the mammary gland tissue [80]. The authors identified 20 metabolites located in hubs and 11 key enzymes were associated with significant changes in expression during mastitis. Many of the enzymes identified were either involved in amino acid metabolism or had a direct connection to amino acid metabolism.

\section{Pigs}

Productivity traits in pig production are those related to meat production, litter sizes, feed consumption, and disease resistance or susceptibility. There are limited studies that have attempted to use biological networks in pig-specific data. Possibly the most relevant study of gene networks in pig productivity traits was an analysis of eQTL performed using whole genome expression microarray using the loin muscle [75]. These authors reported 62 unique eQTL and identified 3 gene networks involved in biological processes related to lipid metabolism, DNA replication, and cell cycle regulation. In addition, they identified 2 potential candidate genes, AKR7A2 and TXNDC12, that were part of the gene network associated with lipid metabolism and their location overlapped with QTL for marbling, intramuscular fat, and loin muscle area. In a similar study, gene networks were inferred from eQTL using RNA obtained from Longissimus dorsi muscle in pigs. The gene networks were inferred from 272 genes having at least one eQTL [48]. Hornshøj et al. [33] reported a novel study of two porcine tissues based on integrative analysis of data from expression profiling of identical samples using cDNA microarray and iTRAQ-based proteomics. They showed that the differences in transcript and protein levels across heart and muscle tissues were positively correlated. These authors did not reconstruct interaction networks but they assessed correlations between protein and transcript levels between microarray and sequencing technologies.

In relation to litter size, differential gene expression analysis was performed using tissues from the ovaries of low and high prolificacy sows during pregnancy [66]. The sows were categorized in high or low prolificacy depending on their breeding values for prolificacy and 6 sows were selected from each class. The analysis identified 189 differentially expressed genes which were involved in immune system activation, regulation of maternal homeostasis by complement and coagulation cascades and lipid and fatty acid metabolism, which may be involved in steroidogenic pathways. The authors also indicated that 22 of the differentially expressed genes were located in the same regions with previously reported QTL for litter size traits.

\section{Poultry}

The completion of the chicken whole genome sequence in 2004 [84] enabled investigations into biological interactions 
[7]. The chicken genome was also used to create a draft genome assembly for the turkey genome completed in 2010 [13]. To explore biological interactions in chicken, an interactome was created using 8,140 genes and established 72,000 interactions [46]. This interactome can be used by specific users to extract sub-networks and study specific biological processes.

Several additional studies have aimed at reconstructing biological networks to study specific traits. For example, Ciraci et al. [11] reconstructed a gene network using genes differentially expressed between endotoxin-stimulated verses non-stimulated macrophages and showed that endotoxin exposure significantly affected the expression of IL1B, IL6, IL8, and TLR15; and Schokker et al. [69] reported a gene network reconstructed using gene expression data associated with intestinal salmonellosis in poultry.

\section{Application of Biological Networks in Animal Breeding}

Recent rapid advances in genomic and bioinformatics technologies have allowed researchers in animal sciences to analyze biological networks, and identify and characterize the molecular components of traits, and the variations associated with them [83]. However, the quantitative aspects of traits do not simply arise from the sum of the properties of individual components of the "trait system" under investigation but depend on dynamic interactions between these components at various biological levels [83]. A summary of genetic interactions was discussed by Drees et al. [15] using a model of two DNA variants/mutations $A$ and $B$ and included:

Noninteractive interaction occurs when $A$ has no effect on the trait when $B$ is present or $B$ has no effect when $A$ is present. However, when $A$ and $B$ have no effect on the trait, but the $A B$ combination has an effect, the interaction is termed Synthetic interaction.

Epistatic interaction occurs when $A$ and $B$ have different effects (in terms of direction or magnitude) but individuals with both mutations have the same phenotype as having either $A$ or $B$. While, when the $A, B$, and the $A B$ combination have the same effect the interaction is named Asynthetic interaction.

Conditional interaction occurs when $A$ has an effect only when $B$ is present, or the $B$ mutant has an effect only when $A$ is present. On the contrary, Suppressive interaction occurs when $A$ has an effect but that effect is abolished by adding the suppressor $B$, which itself shows no singlemutant effect.

Additive interaction: single-mutant effects combine to give a double-mutant effect. A single-nonmonotonic interaction is when $B$ shows opposing effects in the $A$ background, or $A$ shows opposing effects in the
$B$ background, but not both; and a double-nonmonotonic interaction is when both $A$ and $B$ show opposing effects in the background with the other mutant gene.

Therefore, to understand the effects of biological networks on a trait, it is important to evaluate the mode of interactions and the level of dynamicity of the biological networks.

The rationale of the application of biological networks in animal sciences is the development of predictive models of animal traits that help to understand the biology of traits and that can be applied for the prediction, modulation, and improvement of traits [62]. We will attempt to clarify this concept as follows.

The knowledge derived from biological networks, if used optimally, can be used to generate accurate and comprehensive predictions of performance characteristics of animals kept under normal or specified conditions [83]. This can be exemplified by the already existing application of "predictive biology" in "genomic selection," which can be used to predict the breeding value of individual animals in the absence of direct phenotypic measurements. Gene networks in this case would be used to expand the genomic selection models to include the expected interactions between the component markers.

Once the breeding values have been estimated (more accurately) the knowledge of genotype-phenotype relationships and biological interactions may be used for the development of precision-mating systems that maximize the non-additive variation of traits [83]. The mating systems will definitely be superior to the current systems because the current systems rely more on the additive effects of genes, which do not capture the entire contribution from genetic variations [26].

Another important application of biological networks is the sorting of animals to establish the individuals which are best equipped for optimal performance under defined environmental and management conditions [83].

As a result of the biological networks approach, knowledge on the relationships between molecular composition, biological mechanisms, and the behavior of trait systems can developed to create a better understanding of the underlying biological mechanisms associated with the traits and may also aid in the identification of genomic variation causally associated with economically important traits in livestock.

\section{Conclusion}

Following association analysis, reconstruction of biological networks is a critical part in research in livestock science and several other organisms. First, the reconstruction of biological networks is useful in identification of additional 
candidate molecules associated with the phenotype under study. The assumption is that once the molecules associated with a trait have been identified, all molecules that interact with the already identified molecule(s) are considered as potentially associated with the trait. Second, biological networks can be used to identify the biological processes associated with the trait being studied. The biological processes are used to create a better understanding of the underlying biological mechanisms associated with the trait. Therefore, even if a trait is complex and its underlying biological mechanisms are not well understood, biological networks can be used to identify processes that may potentially control the trait. Finally, biological networks can be used to assess interactions between molecules such as genes or proteins. Understanding the interactions may be useful in predicting the effects of manipulating one molecule on the molecules that interact with it. The network may be used to predict the impact of manipulating one trait on other traits that share similar interacting genes.

Due to these benefits, and the ever-increasing amount of molecular data generated by "omics" studies, we anticipate that biological network reconstruction and analysis will remain one of the superior approaches for analysis.

\section{References}

1. Aggrey SE, Karnuah AB, Sebastian B, Anthony NB (2010) Genetic properties of feed efficiency parameters in meat-type chickens. Genet Sel Evol 42:25

2. Andersson L, Georges M (2004) Domestic-animal genomics: deciphering the genetics of complex traits. Nat Rev Genet 5:202-212

3. Arthur PF, Archer JA, Herd RM (2004) Feed intake and efficiency in beef cattle: overview of recent Australian research and challenges for future. Aust J Exp Agr 44:361-369

4. Barabási AL, Gulbahce N, Loscalzo J (2011) Network medicine: a network-based approach to human disease. Nat Rev Genet 12(1):56-68

5. Breitkreutz BJ, Stark C, Tyers M (2003) Osprey: a network visualization system. Genome Biol 4(3):R22. Epub 2003 Feb 27

6. Bulmer MG (1971) The effect of selection on genetic variability. Am Nat 105:201-211

7. Burt DW (2005) Chicken genome: current status and future opportunities. Genome Res 15:1692-1698

8. Caspi R, Foerster H, Fulcher CA, Hopkinson R, Ingraham J, Kaipa P, Krummenacker M, Paley S, Pick J, Rhee SY, Tissier C, Zhang P, Karp PD (2006) MetaCyc: a multiorganism database of metabolic pathways and enzymes. Nucl Acids Res 34(Database issue):D511-D516

9. Ciobanu D, Bastiaansen J, Malek M, Helm J, Woollard J, Plastow G, Rothschild M (2001) Evidence for new alleles in the protein kinase adenosine monophosphate-activated $\gamma 3$-subunit gene associated with low glycogen content in pig skeletal muscle and improved meat quality. Genetics 159(3):1151-1162

10. Ciobanu DC, Bastiaansen JW, Lonergan SM, Thomsen H, Dekkers JC, Plastow GS, Rothschild MF (2004) New alleles in calpastatin gene are associated with meat quality traits in pigs. J Anim Sci 82(10):2829-2839
11. Ciraci C, Tuggle CK, Wannemuehler MJ, Nettleton D, Lamont SJ (2010) Unique genome-wide transcriptome profiles of chicken macrophages exposed to Salmonella-derived endotoxin. BMC Genomics 11:545

12. Curwen V, Eyras E, Andrews TD, Clarke L, Mongin E, Searle SMJ, Clamp M (2006) The ensembl automatic gene annotation system. Genome Res 14(5):942-950

13. Dalloul RA, Long JA, Zimin AV, Aslam L, Beal K (2010) Multiplatform next-generation sequencing of the domestic Turkey (Meleagris gallopavo): genome assembly and analysis. PLoS Biol 8(9):e1000475

14. Dekkers JCM, Hospital F (2002) Utilization of molecular genetics in genetic improvement of plants and animals. Nat Rev Genet 3:22-32

15. Drees BL, Thorsson VN, Carter GV (2005) Derivation of genetic interaction networks from quantitative phenotype data. Genome Biol 6(4):38-39

16. Elsik CG, Tellam RL, Worley KC, The Bovine Genome Sequencing and Analysis Consortium (2009) The genome sequence of taurine cattle: a window to ruminant biology and evolution. Science 324(5926):522-528

17. Evans GJ, Giuffra E, Sanchez A, Kerje S, Davalos G, Vidal O, Illán S, Noguera JL, Varona L, Velander I, Southwood OI, de Koning DJ, Haley CS, Plastow GS, Andersson L (2003) Identification of quantitative trait loci for production traits in commercial pig populations. Genetics 164(2):621-627

18. Fan B, Onteru SK, Plastow GS, Rothschild MF (2009) Detailed characterization of the porcine MC4R gene in relation to fatness and growth. Anim Genet 40(4):401-409

19. Farnir F, Coppieters W, Arranz J, Berzi P, Cambisano N, Grisart B, Karim L, Marcq F, Moreau L, Mni M, Nezer C, Simon P, Vanmanshoven P, Wagenaar D, Georges M (2000) Extensive genomewide linkage disequilibrium in cattle. Genome Res 10:220-227

20. Fisher RA (1918) The correlations between relatives on the supposition of Mendelian inheritance. Philos Trans R Soc Edinb 52:399-433

21. Fortes MRS, Reverter A, Zhang Y, Collis E, Nagaraj SH, Jonsson NN, Prayaga KC, Barris W, Hawken RJ (2010) Association weight matrix for the genetic dissection of puberty in beef cattle. Proc Natl Acad Sci USA 107:13642-13647

22. Fortes MRS, Snelling WM, Reverter A, Nagaraj SH, Lehnert SA, Hawken RJ, DeAtley KL, Peters SO, Silver GA, Rincon G, Medrano JF, Islas-Trejo A, Thomas MG (2012) Gene network analyses of first service conception in Brangus heifers: use of genome and trait associations, hypothalamic-transcriptome information, and transcription factors. J Anim Sci 90:2894-2906

23. Goh K, Cusick ME, Valle D, Childs B, Vidal M, Barabasi AL (2007) The human disease network. PNAS 104(21):8685-8690

24. Grisart B, Coppieters W, Farnir F (2002) Positional candidate cloning of a QTL in dairy cattle: identification of a missense mutation in the bovine DGAT1 gene with major effect on milk yield and composition. Genome Res 12:222-231

25. Groenen MAM, Archibald AL and the swine genome sequencing consortium (2012) Analyses of pig genomes provide insight into porcine demography and evolution. Nature 491:393-398

26. Hallander J, Waldmann P (2007) The effect of non-additive genetic interactions on selection in multi-locus genetic models. Heredity 98:349-359

27. Hartwell LH, Hopfiled JJ, Leiber S, Murray AW (1999) From molecular to modular cell biology. Nature 402(2):C47-C52

28. Hayes B (2007) QTL mapping, MAS and genomic selection. Notes from a short-course organized by Animal Breeding \& Genetics Department of Animal Science Iowa State University. June 4-8, 2007

29. Herd RM, Archer JA, Arthur PF (2003) Reducing the cost of beef production through genetic improvement of feed intake: opportunity and challenges to application. J Anim Sci 81:E9-E17 
30. Hill WG (2010) Understanding and using quantitative genetic variation. Philos Trans R Soc Lond B Biol Sci 365(1537):73-85

31. Hillier LW, International Chicken Genome Sequencing Consortium (2004) Sequence and comparative analysis of the chicken genome provide unique perspectives on vertebrate evolution. Nature 432:695-716

32. Hoque MA, Kadowaki H, Shibata T, Oikawac T, Suzuki K (2009) Genetic parameters for measures of residual feed intake and growth traits in seven generations of Duroc pigs. Livest Sci $121: 45-49$

33. Hornshøj H, Bendixen E, Conley LN, Andersen PK, Hedegaard J, Panitz F, Bendixen C (2009) Transcriptomic and proteomic profiling of two porcine tissues using high-throughput technologies. BMC Genomics 10:30

34. Hudson NJ, Reverter A, Dalrymple BP (2009) A differential wiring analysis of expression data correctly identifies the gene containing the causal mutation. PLoS Comput Biol 5(5):e1000382

35. Jenssen TK, Laegreid A, Komorowski J, Hovig E (2001) Literature network of human genes for high-throughput analysis of gene expression. Nat Genet 28:21-28

36. Jiang Z, Michal JJ, Chen J, Daniels TF, Kunej T, Garcia MD, Gaskins CT, Busboom JR, Alexander LJ, Wright RW Jr, MacNeil MD (2009) Discovery of novel genetic networks associated with 19 economically important traits in beef cattle. Int J Biol Sci. 5(6):528-542

37. Johnson PL, McEwan JC, Dodds KG (2005) A directed search in the region of GDF8 for quantitative trait loci affecting carcass traits in Texel sheep. J Anim Sci 83:1988-2000

38. Junker BH, Schreiber F (eds) (2008) Analysis of biological networks. Wiley series on bioinformatics; computational techniques and engineering. John Wiley and Sons. Hoboken, New Jersey

39. Karp PD, Paley S, Romero P (2002) The Pathway Tools software. Bioinformatics 18(suppl_1):S225-S232

40. Kelley BP, Yuan B, Lewitter F, Sharan R, Stockwell BR, Ideker $T$ (2004) PathBLAST: a tool for alignment of protein interaction networks. Nucl Acids Res 32(Web Server issue):W83-W88

41. Kelly SA, Nehrenberg DL, Hua K, Garland T Jr, Pomp D (2012) Functional genomic architecture of predisposition to voluntary exercise in mice: expression QTL in the brain. Genetics 191(2): 643-654

42. Kim KS, Larsen N, Short T, Plastow G, Rothschild MF (2000) A missense variant of the porcine melanocortin- 4 receptor (MC4R) gene is associated with fatness, growth, and feed intake traits. Mamm Genome 11(2):131-135

43. Kim KS, Thomsen H, Bastiaansen J, Nguyen NT, Dekkers JC, Plastow GS, Rothschild MF (2004) Investigation of obesity candidate genes on porcine fat deposition quantitative trait loci regions. Obes Res 12:1981-1994

44. Kim KS, Lee JJ, Shin HY, Choi BH, Lee CK, Kim JJ, Cho BW, Kim TH (2006) Association of melanocortin 4 receptor (MC4R) and high mobility group AT-hook 1 (HMGA1) polymorphisms with pig growth and fat deposition traits. Anim Genet 37(4):419-421

45. Knight MI, Daetwyler HD, Hayes BJ, Hayden MJ, Ball AJ, Pethick DW, McDonagh MB (2012) Discovery and trait association of single nucleotide polymorphisms from gene regions of influence on meat tenderness and long-chain omega-3 fatty acid content in Australian lamb. Animal Prod Sci 52(7):591-600

46. Konieczka JH, Drew K, Pine A, Belasco K, Davey S, Yatskievych TA, Bonneau R, Antin PB (2009) BioNetBuilder 2.0: bringing systems biology to chicken and other model organism. BMC Genomics 10:S6

47. Kronenberg F (2012) Genetics Meets Metabolomics: from Experiment to Systems Biology, Chapter 15. Springer Science and Business Media, LLC, pp 255-264

48. Liaubet L, Villa-Vialaneix N, Gamot A, Rossi F, Cherel P, Sancristobal M (2010) The structure of a gene network reveals 7 biological sub-graphs underlying eQTLs in pig. Proceedings of WCGALP 2010-World Congress on Genetics Applied to Livestock Production, Allemagne, Leipzig (2010)

49. Liu HC, Cheng HH, Tirunagaru V (2001) A strategy to identify positional candidate genes conferring Marek's disease resistance by integrating DNA microarrays and genetic mapping. Anim Genet 32:351-359

50. MacNeil MD, Nugent RA, Snelling WM (1997) Breeding for Profit: an Introduction to Selection Index Concepts. Range Beef Cow Symposium, Paper 142

51. Maher B (2008) Personal genomes: the case of the missing heritability. Nature 456:18-21

52. Marinus FW, Woelders H, Bannik A (eds) (2011) Systems biology and livestock science. Wiley-Blackwell, UK

53. McPherron AC, Lee S (1997) Double muscling in cattle due to mutations in the myostatin gene. PNAS 94(23):12457-12461

54. Milan D, Jeon JT, Looft C, Amarger V, Robic A, Thelander M, Rogel-Gaillard C, Paul S, Iannuccelli N, Rask L, Ronne H, Lundström K, Reinsch N, Gellin J, Kalm E, Roy PL, Chardon P, Andersson L (2000) A mutation in PRKAG3 associated with excess glycogen content in pig skeletal muscle. Science 288(5469): $1248-1251$

55. Moore KJ (1999) Utilization of mouse models in the discovery of human disease genes. Drug Discov Today 4:123-128

56. Mosher DS, Quignon P, Bustamante CD, Sutter NB, Mellersh CS, Parker HG, Ostrander EA (2007) A mutation in the Myostatin gene increases muscle mass and enhances racing performance in heterozygote dogs. PLoS Genet 3(5):e79. PMC1877876

57. Nagamine $Y$, Pong-Wong R, Navarro P, Vitart V, Hayward C, Rudan I, Campbell H, Wilson J, Wild S, Hicks AA, Pramstaller PP, Hastie N, Wright AF, Haley CS (2012) Localising loci underlying complex trait variation using regional genomic relationship mapping. PLoS ONE 7(10):e46501

58. Nikitin A, Egorov S, Daraselia N, Mazo I (2003) Pathway studio-the analysis and navigation of molecular networks. Bioinformatics Appl Note 19(16):2155-2157

59. Notebaart RA, van Enckevort FH, Francke C, Siezen RJ, Teusink B (2004) Accelerating the reconstruction of genome-scale metabolic networks. BMC Bioinformatics 7:296

60. Pfeiffer T, Soyer OS, Bonhoeffer S (2005) The evolution of connectivity in metabolic networks. PLoS Biol 3(7):e228

61. Pliakogiannis T, Chatzidimitriou C, Evangeliou A, Böhles HJ, Kalaitzidis K (1993) Serum carnitine levels, lipid profile, and metabolic status of patients on continuous ambulatory peritoneal dialysis. Perit Dial Int 13(2):S440-S443

62. Quackenbush J (2007) Extracting biology from high-dimensional biological data. J Exp Biol 210:1507-1517

63. Reshetnikov V, Karpov A, Pot D, Tereshchenko F (2003) Vector PathBlazer: a new pathway analysis and visualization tool. Proc. ISMB

64. Reverter A, Fortes MRS (2012) Building single nucleotide polymorphism-derived gene regulatory networks: Towards functional genome-wide association studies. J Anim Sci. doi:10.2527/jas.2012-5780

65. Reverter A, Hudson NJ, Nagaraj SH, Pérez-Enciso M, Dalrymple BP (2010) Regulatory impact factors: unraveling the transcriptional regulation of complex traits from expression data. Bioinformatics 26(7):896-904

66. Rodriguez AF, Munoz M, Fernandez A, Pena RN, Tomas A, Noguera JL, Ovilo C, Fernandez AI (2011) Differential gene expression in ovaries of pregnant pigs with high and low prolificacy levels and identification of candidate genes for litter size. Biol Reprod 84:299-307

67. Rothschild M, Jacobson C, Vaske D, Tuggle C, Wang L, Short T, Eckardt G, Sasaki S, Vincent A, McLaren D, Southwood O, Van Der Steen H, Mileham A, Plastow G (1996) The estrogen receptor locus is associated with a major gene influencing litter size in pigs. Proc Natl Acad Sci USA 93:201-205 
68. Schenkel FS, Miller SP, Jiang Z, Mandell IB, Ye X, Li H, Wilton JW (2006) Association of a single nucleotide polymorphism in the calpastatin gene with carcass and meat quality traits of beef cattle. J Anim Sci 84(2):291-299

69. Schokker D, Koning DJ, Rebel JMJ, Smits MA (2011) Comp Biochem Physiol D: Genomics Proteomics 6(4):339-347

70. Schwerin M, Kuhn C, Brunner R, Goldammer T, Bennewitz J, Reinsch N, Xu N, Thomsen H, Looft C, Weimann C, Hiendleder S, Erhardt G, Medjugorac I, Forster M, Brenig B, Reinhardt F, Reents R, Russ I, Averdunk G, Blumel J, Kalm E (2004) Animal Science Papers and Reports 22(1):95-100

71. Seo S, Lewin HA (2009) Reconstruction of metabolic pathways for the cattle genome. BMC Syst Biol 3:33

72. Slatkin M (2009) Epigenetic inheritance and the missing heritability problem. Genetics 182:845-850

73. Snelling WM, Cushman RA, Keele JW, Maltecca C, Thomas MG, Fortes MRS, Reverter A (2012) Networks and pathways to guide genomic selection. J Anim Sci. doi:10.2527/jas.2012-5784

74. Sorokin A, Paliy K, Selkov A, Demin OV, Dronov S, Ghazal P, Goryanin I (2006) The pathway editor: a tool for managing complex biological networks. IBM J Res Dev 50(6):561-573

75. Steibel JP, Bates RO, Rosa GJM, Tempelman RJ, Rilington VD et al (2011) Genome-wide linkage analysis of global gene expression in loin muscle tissue identifies candidate genes in pigs. PLoS ONE 6(2):e16766

76. Strohman R (2002) Maneuvering in the complex path from genotype to phenotype. Science 296:701-703

77. Sutter NB, Bustamante CD, Chase K, Gray MM, Zhao K, Zhu L, Padhukasahasram B, Karlins E, Davis S, Jones PG, Quignon P, Johnson GS, Parker HG, Fretwell N, Mosher DS, Lawler DF, Satyaraj E, Nordborg M, Lark KG, Wayne RK, Ostrander EA (2007) A single IGF1 allele is a major determinant of small size in dogs. Science 316(5821):112-115

78. Szyndler-Nędza M, Tyra M, Blicharski T, Piorkowska K (2010) Effect of mutation in MC4R gene on carcass quality in Pulawska pig included in conservation breeding programme. Animal Science Papers and Reports 28(1):37-45

79. Wagner GP, Kenney-Hunt JP, Pavlicev M, Peck JR, Waxman D, Cheverud JM (2008) Pleiotropic scaling of gene effects and the 'cost of complexity'. Nature 452(7186):470-472

80. Wang C, Wang J, Ju Z, Zhai R, Zhou L, Li Q, Li J, Li R, Huang J, Zhong J (2012) Reconstruction of metabolic network in the bovine mammary gland tissue. Mol Biol Rep 39(7):7311-7318

81. Wang Y, Gjuvsland AB, Vik JO, Smith NP, Hunter PJ et al (2012) Parameters in dynamic models of complex traits are containers of missing heritability. PLoS Comput Biol 8(4): e1002459

82. Weikard R, Altmaier E, Suhre K, Weinberger KM, Hammon HM, Albrecht E, Setoguchi K, Takasuga A, Kühn C (2010) Metabolomic profiles indicate distinct physiological pathways affected by two loci with major divergent effect on Bos taurus growth and lipid deposition. Physiol Genomics 42A(2):79-88

83. Woelders H, Te Pas MFW, Bannink A, Veerkamp RF, Smits MA (2011) Systems biology in animal sciences. Animal 5(7):1036-1047

84. Wong GK, Liu B, Wang J, Zhang Y, Yang X, Zhang Z, Meng Q, Zhou J, Li D, Zhang J et al (2004) A genetic variation map for chicken with 2.8 million single-nucleotide polymorphisms. Nature 432:717-722

85. Yao D, Wang J, Lu Y, Noble N, Sun H, Zhu X, Lin N, Payan DG, Li M, Qu K (2004) PathwayFinder: bridging the way towards automatic pathway extraction. ACM International Conference Proceeding Series, 2004

86. Zhu M, Zhao S (2007) Candidate gene identification approach: progress and challenges. Int. J. Biol. Sci 3(7):420-427

87. Zoubarev A (2009) Tools for visual analysis of biological networks. www.cs.ubc.ca. (15th Feb 2013)

88. Zupan B, Demsar J, Bratko I, Juvan P, Halter JA, Kuspa A, Shaulsky G (2003) GenePath: a system for automated construction of genetic networks from mutant data. Bioinformatics 19(3): 383-389 